\title{
A Biomechanical Study of Double-row Suture-bridge and Double- screw Fixation Strength in Split-type Greater Tuberosity Fractures of the Humerus
}

\author{
Man Ma \\ Peking University People's Hospital \\ Xiaomeng Zhang \\ Peking University People's Hospital \\ Yanhua Wang \\ Peking University People's Hospital \\ Dianying Zhang ( $\nabla$ zdy8016@163.com) \\ Peking University People's Hospital
}

\section{Research article}

Keywords: Double-row suture-bridge fixation, Double-screw fixation, Split-type greater tuberosity fracture, Fixation strength, Fracture displacement

Posted Date: November 20th, 2020

DOI: https://doi.org/10.21203/rs.3.rs-107462/v1

License: (1) This work is licensed under a Creative Commons Attribution 4.0 International License. Read Full License 


\section{Abstract}

Background: This study aimed to compare the fixation strength of double-row suture-bridge (DR) and double-screw (DS) fixation methods in treating split-type greater tuberosity fracture of the humerus.

Methods: We established 24 fracture models of frozen pig shoulders with reserved supraspinatus, infraspinatus, and teres minor muscles. The specimens were randomly divided into two groups according to the fixation methods of double-row suture-bridge (group A) and double screws (group B). The loads of 3-mm displacement, 5-mm displacement, and fixation failure of each group were measured using a biomechanical device in both traction directions of the supraspinatus muscle (horizontal direction) and infraspinatus-teres minor muscles (vertical backward direction).

Results: In the direction of supraspinatus traction, there was no statistical difference in the mean load values of 3-mm displacement, 5-mm displacement, and fixation failure in both groups $(p>0.05)$. In the direction of infraspinatus-teres minor traction, the mean load values of 3$\mathrm{mm}$ displacement, 5-mm displacement, and fixation failure of double-screw fixation were greater than those of double-row suture-bridge fixation $(p=0.000)$.

Conclusion: The fixation strength of double-screw suture-bridge and double screws were equivalent in the direction of the supraspinatus. However, the fixation strength of double-screw suture-bridge was less than that of double screws, indicating poor anti-rotation property. Double-screw suture-bridge fixation alone is not recommended to treat split-type greater tuberosity fracture with a large fragment.

\section{Introduction}

Greater tuberosity fractures account for approximately $13-33 \%$ of proximal humeral fractures, $14-20 \%$ of which are isolated fractures. These fractures primarily occur in middle-aged men and are often accompanied by shoulder dislocation or rotator cuff injury [1-3]. In recent years, some scholars have proposed that operation should be performed in patients with fragment displacement over $5 \mathrm{~mm}$, and in cases with fragment displacement over $3 \mathrm{~mm}$, surgical treatment is essential to heavy workers and athletes with high requirements for a large amount of excise or frequent overhead activities [4, 5]. Mutch et al. [6] proposed a classification system for isolated greater tuberosity fracture based on its characteristics, including avulsion type, compression type, and split type, and they found that the split-type fractures were more common. Several fixation methods are available for split-type greater tuberosity fracture with pros and cons of each own, but they still remain highly controversial without any gold standard. In terms of mechanics, the supraspinatus, infraspinatus, and teres minor tendons are attached to the humeral greater tuberosity, pulling the fragment toward posterosuperior direction [7-9]. This type of fracture requires anatomic reduction and rigid fixation to avoid further redisplacement. The current foreign and domestic studies mainly focus on the fixation strength in the traction direction of the supraspinatus, and insufficient attention was paid to that of the infraspinatus and teres minor. Therefore, we designed this experiment to verify the biomechanical strength of two commonly used fixation methods and compared their fixation strength in both traction directions of the supraspinatus and infraspinatus-teres minor muscles, aiming to provide a biomechanical basis to treat isolated split-type greater tuberosity fractures of the humerus.

\section{Materials And Methods}

The porcine shoulder specimens used were purchased on the market, and no ethical review was required after consultation with the Medical Ethics Committee of Peking University People's Hospital.

\section{Specimen preparation}

We used 12 pairs of fresh frozen 6-month-old female porcine shoulders ( 24 in total) for this study. The bone mineral density of a 6-month-old female pig is similar to that of normal young adults. The porcine shoulder is widely used in mechanical experimental research, and the results have been widely recognized [10-12]. The skin, subcutaneous soft tissue, superficial fascia, and deep fascia were removed from all shoulder specimens, and 4-cm muscle-tendon stumps of the supraspinatus, infraspinatus, and teres minor at the proximal end of the greater tuberosity were preserved. The greater tuberosity was cut using a swing saw along the marked outline to establish the fracture model. The length from the vertex of the greater tuberosity to the distal humerus was $15 \mathrm{~cm}$, and with horizontal osteotomy, the distal end of the humerus was embedded in a 10- $\times 5-\times 5-\mathrm{cm}$ container made of denture powder. The specimens were randomly divided into two groups with 12 specimens in each, and the corresponding methods were used for fracture fixations. A single 2-mm-diameter wire rope was used for continuous hemstick suture to ensure neat edges and firm stress.

(1) Double-row suture-bridge (group A): Two medial-row suture anchors ( $5.0 \mathrm{~mm}$, Helix, Johnson \& Johnson) were implanted in the proximal part of the fragment with an angulation of $45^{\circ}$, and the distance between the screws was $1.5 \mathrm{~cm}$. The sutures (No.2 FiberWire) were knotted 
after passing through the rotator cuff tendon attached to the greater tuberosity. Two lateral-row suture anchors (Versalok, Johnson \& Johnson) were placed aligned with the medial-row suture anchors and $5 \mathrm{~mm}$ distal to the fragment. The sutures were passed through the Versalok anchors to form a mesh and then tightened to fix the fragment. (Fig. 1, a). Double-screw (group B): Two 6.5-mm cancellous bone screws with washers were implanted in the central area of the fragment without penetrating the humeral head (Fig. 1, b).

\section{Biomechanical testing}

The specimens were positioned in the electron-tensile tester (AG-IS MO; Shimadzu Corp., Tokyo, Japan). The pulling directions were set the same as the traction directions of the supraspinatus muscle and infraspinatus-teres minor muscles. The $0^{\circ}$ position of shoulder joint was selected as the test position to more effectively simulate shoulder abduction.

Before the experiment, we applied $0-50 \mathrm{~N}$ at a speed of $5 \mathrm{~mm} / \mathrm{min}$ to each specimen three times to eliminate soft tissue adhesion and improve the reliability and repeatability of data. After preconditioning, all specimens were loaded at a constant speed of $10 \mathrm{~mm} / \mathrm{min}$. The tensile forces of two fixation methods in two traction directions were measured when the greater tuberosity fragment displaced $3 \mathrm{~mm}, 5 \mathrm{~mm}$, and loaded to failure (internal fixation failure, fracture or displacement of over $1 \mathrm{~cm}$ ), respectively. The load-displacement curves of each group were recorded (Figs. 2-5).

\section{Statistical analysis}

The data were analyzed by SPSS 20.0 (IBM SPSS, Inc., Chicago, IL, USA). The mean between the two groups was compared by an Independent-Sample T-test. $P<0.05$ was set as the difference level, and $P<0.001$ was set as the significant difference level.

\section{Results}

\section{Comparison of two groups in the vertical backward traction direction}

In the direction of supraspinatus traction, there were no significant differences in the fixation strength between the two groups $(P=0.802, P=$ 0.119 , and $P=0.914$ ). All the samples in group $A$ had displacements of over $1 \mathrm{~cm}$, and in group $\mathrm{B}, 4$ samples had humeral head fracture on the screw level, and 2 samples had displacements of over $1 \mathrm{~cm}$ (Table 1).

Table 1 Load values of two internal fixation methods at the displacements of $3 \mathrm{~mm}, 5 \mathrm{~mm}$, and load to failure in the traction direction of supraspinatus

\begin{tabular}{|c|c|c|c|c|c|c|c|c|c|c|}
\hline Displacements & Groups & $\begin{array}{l}\text { Sample } \\
1\end{array}$ & $\begin{array}{l}\text { Sample } \\
2\end{array}$ & $\begin{array}{l}\text { Sample } \\
3\end{array}$ & $\begin{array}{l}\text { Sample } \\
4\end{array}$ & $\begin{array}{l}\text { Sample } \\
5\end{array}$ & $\begin{array}{l}\text { Sample } \\
6\end{array}$ & $\bar{x} \pm s$ & $\begin{array}{l}D \\
\text { value }\end{array}$ & $\begin{array}{l}P \\
\text { value }\end{array}$ \\
\hline \multirow[t]{2}{*}{$3 \mathrm{~mm}$} & A & $191.25 \mathrm{~N}$ & $180.06 \mathrm{~N}$ & $155.38 \mathrm{~N}$ & $178.31 \mathrm{~N}$ & $193.69 \mathrm{~N}$ & $173.56 \mathrm{~N}$ & $178.71 \pm 13.82 \mathrm{~N}$ & \multirow[t]{2}{*}{3.200} & \multirow[t]{2}{*}{0.082} \\
\hline & B & $153.25 N$ & $198.88 \mathrm{~N}$ & $152.81 \mathrm{~N}$ & $175.31 \mathrm{~N}$ & $188.69 \mathrm{~N}$ & $222.50 \mathrm{~N}$ & $181.91 \pm 27.18 \mathrm{~N}$ & & \\
\hline \multirow[t]{2}{*}{$5 \mathrm{~mm}$} & A & $307.31 \mathrm{~N}$ & $287.94 \mathrm{~N}$ & $261.06 \mathrm{~N}$ & $301.50 \mathrm{~N}$ & $289.25 \mathrm{~N}$ & $266.69 N$ & $285.63 \pm 18.45 \mathrm{~N}$ & \multirow[t]{2}{*}{14.900} & \multirow[t]{2}{*}{0.19} \\
\hline & B & $320.19 N$ & $297.00 \mathrm{~N}$ & $291.00 \mathrm{~N}$ & $271.69 \mathrm{~N}$ & $300.56 \mathrm{~N}$ & $322.69 \mathrm{~N}$ & $300.52 \pm 19.04 \mathrm{~N}$ & & \\
\hline \multirow{2}{*}{$\begin{array}{l}\text { Fixation } \\
\text { failure }\end{array}$} & A & $493.50 \mathrm{~N}$ & $442.94 \mathrm{~N}$ & $412.38 \mathrm{~N}$ & $445.69 \mathrm{~N}$ & $433.75 \mathrm{~N}$ & $413.63 N$ & $440.32 \pm 29.66 \mathrm{~N}$ & \multirow[t]{2}{*}{3.010} & \multirow[t]{2}{*}{0.914} \\
\hline & B & $487.44 \mathrm{~N}$ & $452.56 \mathrm{~N}$ & $425.38 N$ & $334.75 \mathrm{~N}$ & $498.94 N$ & $460.88 \mathrm{~N}$ & $443.33 \pm 59.23 \mathrm{~N}$ & & \\
\hline
\end{tabular}

\section{Comparison of two groups in the horizontal traction direction}

In the direction of infraspinatus-teres minor traction, the loading force in group B was significantly greater than that in group $\mathrm{A}(P=0.000, P$ $=0.000$, and $P=0.000$ ). All the samples in group $A$ had displacements of over $1 \mathrm{~cm}$, and in group $B, 5$ samples had displacements of over $1 \mathrm{~cm}$, and 1 sample had greater tuberosity fracture on the level of the proximal screw (Table 2).

Table 2 Load values of two internal fixation methods at the displacements of $3 \mathrm{~mm}, 5 \mathrm{~mm}$, and load to failure in the traction direction of infraspinatus-teres minor 


\begin{tabular}{|c|c|c|c|c|c|c|c|c|c|c|}
\hline Displacements & Groups & $\begin{array}{l}\text { Sample } \\
1\end{array}$ & $\begin{array}{l}\text { Sample } \\
2\end{array}$ & $\begin{array}{l}\text { Sample } \\
3\end{array}$ & $\begin{array}{l}\text { Sample } \\
4\end{array}$ & $\begin{array}{l}\text { Sample } \\
5\end{array}$ & $\begin{array}{l}\text { Sample } \\
6\end{array}$ & $\bar{x} \pm s$ & $D$ value & $\begin{array}{l}P \\
\text { value }\end{array}$ \\
\hline \multirow[t]{2}{*}{$3 \mathrm{~mm}$} & A & $74.19 \mathrm{~N}$ & $57.44 \mathrm{~N}$ & $100.88 \mathrm{~N}$ & $81.19 \mathrm{~N}$ & $81.38 \mathrm{~N}$ & $102.56 \mathrm{~N}$ & $82.94 \pm 16.97 \mathrm{~N}$ & \multirow[t]{2}{*}{144.400} & \multirow[t]{2}{*}{0.000} \\
\hline & B & $231.13 \mathrm{~N}$ & $227.06 \mathrm{~N}$ & $211.69 \mathrm{~N}$ & $231.01 \mathrm{~N}$ & $252.31 \mathrm{~N}$ & $210.81 \mathrm{~N}$ & $227.34 \pm 15.29 \mathrm{~N}$ & & \\
\hline \multirow[t]{2}{*}{$5 \mathrm{~mm}$} & $A$ & $111.13 \mathrm{~N}$ & $93.19 \mathrm{~N}$ & $134.94 \mathrm{~N}$ & $146.56 \mathrm{~N}$ & $118.02 \mathrm{~N}$ & $140.50 \mathrm{~N}$ & $124.06 \pm 20.26 \mathrm{~N}$ & \multirow[t]{2}{*}{198.290} & \multirow[t]{2}{*}{0.000} \\
\hline & B & $262.01 \mathrm{~N}$ & $314.88 \mathrm{~N}$ & $315.63 N$ & $325.94 \mathrm{~N}$ & $351.51 \mathrm{~N}$ & $364.13 \mathrm{~N}$ & $322.35 \pm 35.64 \mathrm{~N}$ & & \\
\hline \multirow{2}{*}{$\begin{array}{l}\text { Fixation } \\
\text { failure }\end{array}$} & A & $188.81 \mathrm{~N}$ & $123.06 \mathrm{~N}$ & $224.13 \mathrm{~N}$ & $217.38 \mathrm{~N}$ & $192.00 \mathrm{~N}$ & $243.56 \mathrm{~N}$ & $198.16 \pm 42.12 \mathrm{~N}$ & \multirow[t]{2}{*}{268.890} & \multirow[t]{2}{*}{0.000} \\
\hline & B & $433.38 N$ & $515.13 \mathrm{~N}$ & $443.81 \mathrm{~N}$ & $488.88 \mathrm{~N}$ & $506.51 \mathrm{~N}$ & $516.56 \mathrm{~N}$ & $484.05 \pm 36.71 \mathrm{~N}$ & & \\
\hline
\end{tabular}

\section{Comparison of load values in each group in two traction directions}

In group $A$, the loading force in the supraspinatus traction direction was significantly greater than that in the infraspinatus-teres minor traction direction $(P=0.000, P=0.000$, and $P=0.000)$. In group $\mathrm{B}$, the loading force in the infraspinatus-teres minor traction direction was greater than that in the supraspinatus traction direction $(P=0.005)$. However, there were no significant differences in the load to 5 -mm displacements or load to failure $(P=0.215$ and $P=0.183)$.

In group $A$, the loading force in the supraspinatus traction direction was significantly greater than that in the infraspinatus-teres minor traction direction $(P=0.000, P=0.000$, and $P=0.000)$. In group $B$, the loading force in the infraspinatus-teres minor traction direction was greater than that in the supraspinatus traction direction $(P=0.005)$. However, there were no significant differences in the load to 5 -mm displacements or load to failure $(P=0.215$ and $P=0.183)$ (Table 3$)$.

Table 3

Comparison of load values in each group at the displacements of $3 \mathrm{~mm}, 5 \mathrm{~mm}$, and load to failure in two traction directions

\begin{tabular}{|lllll|}
\hline Displacements & Groups & Horizontal traction direction & Vertical backward traction direction & $P$ value \\
\hline $3 \mathrm{~mm}$ & $\mathrm{~A}$ & $178.71 \pm 13.82 \mathrm{~N}$ & $82.94 \pm 16.97 \mathrm{~N}$ & 0.000 \\
\cline { 2 - 4 } & $\mathrm{B}$ & $181.91 \pm 27.18 \mathrm{~N}$ & $227.34 \pm 15.29 \mathrm{~N}$ & 0.005 \\
\hline $5 \mathrm{~mm}$ & $\mathrm{~A}$ & $285.63 \pm 18.45 \mathrm{~N}$ & $124.06 \pm 20.26 \mathrm{~N}$ & 0.000 \\
\hline & $\mathrm{B}$ & $300.52 \pm 19.04 \mathrm{~N}$ & $322.35 \pm 35.64 \mathrm{~N}$ & 0.215 \\
\hline Fixation failure & $\mathrm{A}$ & $285.63 \pm 18.45 \mathrm{~N}$ & $124.06 \pm 20.26 \mathrm{~N}$ & 0.000 \\
\cline { 2 - 5 } & $\mathrm{B}$ & $300.52 \pm 19.04 \mathrm{~N}$ & $322.35 \pm 35.64 \mathrm{~N}$ & 0.215 \\
\hline
\end{tabular}

\section{Discussion}

We designed this biomechanical experiment based on the anatomical characteristics of the greater tuberosity and rotator cuff as well as the biomechanical characteristics of fragment displacement to compare the fixation strength of two commonly used internal fixation methods to treat split-type greater tuberosity fracture in two traction directions of the supraspinatus and infraspinatus-teres minor muscles. The supraspinatus plays a major role within the range of shoulder abduction less than $15^{\circ}$, while the infraspinatus and teres minor muscles are mainly involved in the external rotation of the shoulder joint [13]. The displacement of the greater tuberosity fragment results in the instability of the rotator cuff and dysfunction of the shoulder joint. Therefore, we should pay attention to the fixation strength in both directions of shoulder abduction and external rotation. In recent years, researches on this type of fracture have focused primarily on fixation strength in the direction of supraspinatus traction. A study by Seppel et al. [14] utilizing 12 cadaver bones showed no statistical difference in the fixation strength of single-row and double-row anchors in the treatment of split-type greater tuberosity fracture. Lin et al. [15] compared the fixation methods of double-row suture anchor, double-row suture-bridge, and double-screw fixation in the direction of supraspinatus traction. When loaded to the 3-mm displacement, the fixation strength of double-row suture-bridge was stronger than that of other two fixation methods. When loaded to 5-mm displacement and failure, there was no statistical difference between double-row suture-bridge and double-row suture anchor, which were stronger than that of double-screw fixation. However, no studies have been reported on the fixation strength in the direction of infraspinatus-teres minor traction. The external rotation induced by infraspinatus and teres minor has not been 
paid much attention in clinic due to long-term immobilization and early limitations of external rotation of the shoulder joint after operation. To avoid shoulder joint stiffness resulting from long-term immobilization, early rehabilitation is essential but relies on the rigid fixation in both directions.

The double-row suture-bridge has been widely used in clinic, which can effectively resist the traction of the supraspinatus and prevent the postoperative redisplacement of the greater tuberosity fragment [16, 17]. However, this technique is more suitable for avulsion fractures of rotator cuff tendon attachment as well as rotator cuff tear [18]. For split-type greater tuberosity fracture with a large fragment, the suture anchor fixation is an elastic method, which may have shortcomings such as poor strength, anchor pulling out, rotator cuff cutting, etc., and its efficacy is controversial $[19,20]$. In our study, the fixation strength of double-row suture-bridge technique has poor fixation strength to resist rotation in the direction of infraspinatus-teres minor traction. Therefore, it is not suitable for this type of fracture.

The double-screw technique has a strong advantage in the fixation of cancellous bone fracture. With cancellous lag screws, the fracture was rigidly fixed with compression. In this experiment, we found that the fixation strength of double screws was equal to that of double-row suture anchor in the supraspinatus traction direction, but greater than that of double-row suture anchor in the infraspinatus-teres minor traction direction. Moreover, double-screw fixation can be completed under arthroscopy with minimal incisions, or with a percutaneous method to reduce further damage to soft tissue and blood supply $[21,22,23]$. In recent years, absorbable screws have been introduced, which can reduce the burden of secondary surgery, avoid metal reaction, and reduce the phenomenon of stress shielding [24].

However, double-screw fixation also has defects, and the fixation strength is less than that of locking plate or tension band, and under continuous supraspinatus traction, the fracture fragment is easily displaced, making the internal fixation ineffective [25, 26]. Double-screw fixation with washers increases the risk of acromial impingement. Furthermore, for patients with osteoporosis or comminuted fragments, it is impossible to obtain instability [27].

Clinically, various mechanical factors affect the greater tuberosity of the humerus. The major limitation of this experiment is that the in vitro biomechanical experiments can only simulate the instantaneous fixation strength but not dynamic mechanical changes in the process of shoulder movement, which requires further investigation.

\section{Conclusion}

The fixation strength of both double-row suture-bridge and double screws are equivalent in the direction of supraspinatus traction. However, double-screw fixation provides greater fixation strength compared with that of double-row suture-bridge in the direction of infraspinatus-teres minor traction. The double-row suture-bridge fixation method has poor anti-rotation property, which requires long-term postoperative immobilization to prevent fragment displacement. Thus, DR fixation alone is not recommended for isolated split-type greater tuberosity fracture of the humerus. In contrast, double-screw fixation is more suitable for this type of fracture with advantages in mechanical capacity.

\section{Declarations}

\section{Acknowledgements}

None

\section{Authors' contributions}

$M M, X Z$, and $Y X$ did data collection and analysis, MM and DZdid study design and proofing, $X Z$ did manuscript writing. The authors read and approved the final manuscript.

\section{Funding}

This work was financially supported by Natural Science Foundation of China (316781246, 31640045), and National Key Research and Development Project (2016YFC1101600).

\section{Availability of data and materials}

Not applicable.

\section{Ethics approval and consent to participate}

Not applicable. 


\section{Consent for publication}

All authors consent for the publication.

\section{Competing interests}

None

\section{References}

1. Rajesh KR (2001) The translated two-part fracture of the proximal humerus. J Bone Joint Surg Br 83(6): 775-776.

2. Gruson KI, Ruchelsman DE, Tejwani NC (2008) Isolated tuberosity fractures of the proximal humerus: Current concepts. Injury 39(3): 284-298. https://doi.org/10.1016/j.injury.2007.09.022

3. Kim E, Shin HK, Kim CH (2005) Characteristics of an isolated greater tuberosity fracture of the humerus. J Orthop Sci 10(5): 441-444. https://doi.org/10.1007/s00776-005-0924-6

4. Park TS, Choi IY, Kim YH, et al (1997) A new suggestion to the treatment of minimal displaced fractures of the greater tuberosity of the proximal humerus. Bull Hosp Jt Dis 56(3): 171-176.

5. Platzer P, Kutscha-Lissberg F, Lehr S, et al (2005) The influence of displacement on shoulder function in patients with minimally displaced fractures of the greater tuberosity. Injury 36(10): 1185-1189. https://doi.org/10.1016/j.injury.2005.02.018

6. Mutch J, Laflamme GY, Hagemeister N, et al (2014) A new morphological classification for greater tuberosity fractures of the proximal humerus $\rrbracket$ us: validation and clinical implications. Bone Joint J 96(5): 646-651. https://doi.org/10.1302/0301-620X.96B5.32362

7. Minagawa H, Itoi E, Konno N, et al (1998) Humeral attachment of the supraspinatus and infraspinatus tendons: an anatomic study. Arthroscopy 14(3): 302-306. https://doi.org/10.1016/s0749-8063(98)70147-1

8. Debottis D, Anavian J, Green A (2014) Surgical Management of Isolated Greater Tuberosity Fractures of the Proximal Humerus. Orthop Clin North Am 45(2): 207-218. https://doi.org/10.1016/j.ocl.2013.12.007

9. Bono CM, Renard R, Levine RG, et al (2001) Effect of displacement of fractures of the greater tuberosity on the mechanics of the shoulder. J Bone Joint Surg Br 83(7): 1056-62. https://doi.org/10.1302/0301-620x.83b7.10516

10. Petit CJ, Boswell R, Mahar A, et al (2003) Biomechanical Evaluation of a New Technique for Rotator Cuff Repair. Am J Sports Med 31(6): 849-853. https://doi.org/10.1177/03635465030310062001

11. Lorbach O, Bachelier F, Vees J, et al (2008) Cyclic loading of rotator cuff reconstructions: single-row repair with modified suture configurations versus double-row repair. Am J Sports Med 36(8): 1504-1510. https://doi.org/10.1177/0363546508314424

12. Lin CL, Su FC, Chang CH, et al (2015) Effect of shoulder abduction on the fixation of humeral greater tuberosity fractures: a biomechanical study for three types of fixation constructs. J Shoulder Elbow Surg 24(4): 547-554. https://doi.org/10.1016/j.jse.2014.09.032

13. Xu D, Wen G, Huang M (2010) Anatomical features of rotator cuff. Zhongguo Guanjie Waike Zazhi 4(1): 63-64.

14. Seppel G, Saier T, Martetschl Ger F, et al (2017) Single versus double row suture anchor fixation for greater tuberosity fractures-a biomechanical study. BMC Musculoskelet Disord 18(1): 506. https://doi.org/10.1186/s12891-017-1868-7

15. Lin CL, Hong CK, Jou IM, et al (2012) Suture anchor versus screw fixation for greater tuberosity fractures of the humerus-a biomechanical study. J Orthop Res 30(3): 423-428. https://doi.org/10.1002/jor.21530

16. Jang SH, Song HE, Choi SH (2018) Arthroscopic percutaneous inverted mattress suture fixation of isolated greater tuberosity fracture of humerus. J Orthop Surg (Hong Kong) 26(1): 2309499017754108. https://doi.org/10.1177/2309499017754108

17. Ji JH, Jeong JJ, Kim YY, et al (2017) Clinical and radiologic outcomes of arthroscopic suture-bridge repair for the greater tuberosity fractures of the proximal humerus. Arch Orthop Trauma Surg 137(1): 9-17. https://doi.org/10.1007/s00402-016-2586-6

18. Rouleau DM, Mutch J, Laflamme GY (2016) Surgical Treatment of Displaced Greater Tuberosity Fractures of the Humerus. J Am Acad Orthop Surg 24(1): 46-56. https://doi.org/10.5435/JAAOS-D-14-00289

19. Ji JH, Kim WY, Ra KH (2007) Arthroscopic Double-Row Suture Anchor Fixation of Minimally Displaced Greater Tuberosity Fractures. Arthroscopy 23(10): 1133.e1-4. https://doi.org/10.1016/j.arthro.2006.11.029

20. Levy DM, Erickson BJ, Harris JD, et al (2017) Management of Isolated Greater Tuberosity Fractures: A Systematic Review. Am J Orthop (Belle Mead NJ) 46(6): 445-453.

21. Wang Y, Zhao J, Huang X (2012) Arthroscopic reduction and fixation for isolated greater tuberosity fractures. Chin Med 12(2): 12721275. 
22. Dimakopoulos P, Panagopoulos A, Kasimatis G (2007) Transosseous suture fixation of proximal humeral fractures. J Bone Joint Surg Am 89(8): 1700-1709. https://doi.org/10.2106/JBJS.F.00765

23. Yoon $\mathrm{TH}$, $\mathrm{Choi} \mathrm{CH}$, Choi YR, et al (2018) Clinical outcomes of minimally invasive open reduction and internal fixation by screw and washer for displaced greater tuberosity fracture of the humerus. J Shoulder Elbow Surg 27(6): e173-e177. https://doi.org/10.1016/j.jse.2017.11.029

24. Dang Y, Fu Z, Lu H, et al (2009) Arthroscopic assisted treatment of shoulder dislocation combined with greater tuberosity fracture. Zhongguo Xiu Fu Chong Jian Wai Ke Za Zhi 23(3): 271-273.

25. Braunstein V, Wiedemann E, Plitz W, et al (2007) Operative treatment of greater tuberosity fractures of the humerus - A biomechanical analysis. Clin Biomech (Bristol, Avon) 22(6): 652-657. https://doi.org/10.1016/j.clinbiomech.2007.03.002

26. Jang SH, Song HE, Choi SH (2018) Arthroscopic percutaneous inverted mattress suture fixation of isolated greater tuberosity fracture of humerus. J Orthop Surg (Hong Kong) 26(1): 2309499017754108. https://doi.org/10.1177/2309499017754108

27. Levy DM, Erickson BJ, Harris JD, et al (2017) Management of Isolated Greater Tuberosity Fractures: A Systematic Review. Am J Orthop (Belle Mead NJ) 46(6): 445-453

\section{Figures}

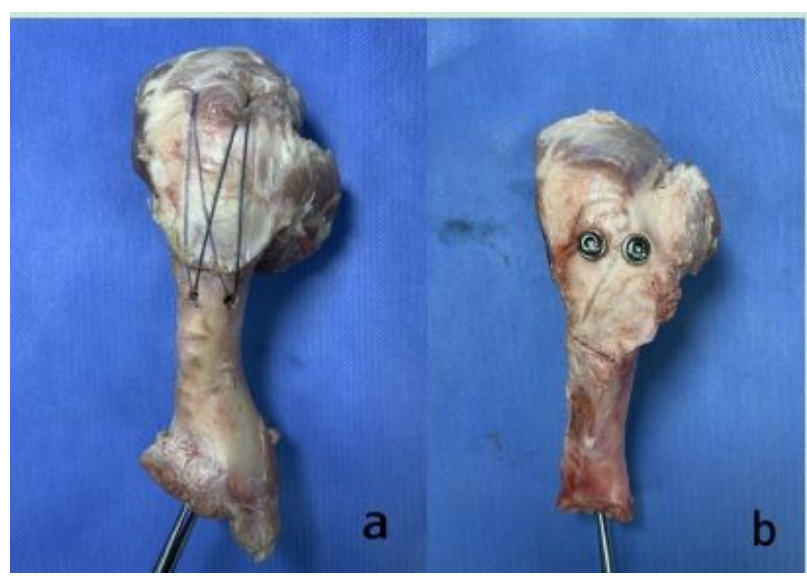

\section{Figure 1}

Two fixation methods: a: double row suture-bridge; b: two screws 